\title{
CATHETER RELATED INFECTION IN HEMODIALYSIS PATIENTS WITH DOUBLE LUMEN CATHETER.
}

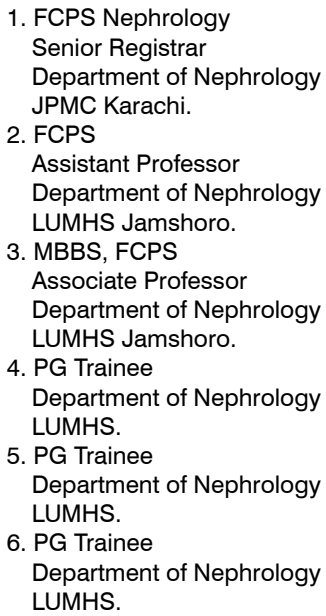

Correspondence Address: Dr. Santosh Kumar Department of Nephrology LUMHS Jamshoro.

dr_santosh72@yahoo.com

Article received on: 19/06/2018

Accepted for publication: $16 / 05 / 2019$

Received after proof reading: $31 / 07 / 2019$

\begin{abstract}
Muhammad Ali ${ }^{1}$, Bhagwan Das ${ }^{2}$, Santosh Kumar ${ }^{3}$, Rafia Memon ${ }^{4}$, Bella Dayu ${ }^{5}$, Babeeta ${ }^{6}$
ABSTRACT... Catheter related infections are common issue, a major cause of morbidity and mortality in patients with uremia. Clinical findings, including fever, redness, or tenderness at catheter site are unreliable for the diagnosis of catheter-related infection due to poor sensitivity and specificity. Study Design: Descriptive Cross sectional Study. Setting: Department of Nephrology, Jinnah Postgraduate Medical Centre, Karachi. Period: September 2014 to March 2015. Materials and Methods: All patients with age 25-50 years of either gender undergoing hemodialysis via double-lumen catheter were enrolled. Regular monitoring of temperature and WBC counts was carried out. If a patient develops fever (100 F or more) or leukocytosis (TLC $12,000 / \mathrm{mcl}$ ), a through re-examination, urinalysis and chest X-ray was done to exclude other causes of infection in this patient. Blood cultures from catheter tip and a peripheral blood culture was sent. Growth of the organism from both the cultures was noted and catheter related infection was termed positive if same organism $s$ found to be present in both the cultures. Results: Mean age of the patients was $42.69 \pm 6.86$ years. There were $75(58.10 \%)$ females and $54(41.90 \%)$ males. In majority of the patients, site of catheter was right internal jugular vein $54(41.90 \%)$, followed by femoral vein $30(23.30 \%)$, left internal jugular vein $24(18.60 \%)$ and subclavian vein in $21(16.30 \%)$ patients. Frequency of catheter related infection was found to be $19(14.70 \%)$. Conclusion: The frequency of catheter related infection was found in 19 (14.70\%) patients undergoing hemodialysis via double-lumen catheter.
\end{abstract}

Key words: Catheter Related Infection, Culture, Double-Lumen Catheter, Hemodialysis

Article Citation: Ali M, Das B, Kumar S, Memon R, Dayu B, Babeeta. Catheter related infection in hemodialysis patients with double lumen catheter. Professional Med J 2019; 26(8):1278-1282. DOI: 10.29309/TPMJ/2019.26.08.3869

\section{INTRODUCTION}

In patients with uremia, central venous catheterization with double-lumen catheter is a useful method to gain venous access for hemodialysis and IV medication. ${ }^{1}$ Tunneled and cuffed double lumen catheters are being increasingly used for acute purposes as well as a bridge will the more permanent vascular access like arteriovenous fistula is matured. ${ }^{2}$

Catheter related infections are common issue, a major cause of morbidity and mortality in these patients. It was found in 101 hemodialysis patients in one study that bacteremia risk in venous catheters on average was 5.5 episodes per 1000 catheter days. ${ }^{3}$ The overall death rate in hemodialysis patients thru central venous catheters is $34 \% .{ }^{4}$ In one study bacteremia due to Staphylococcus organism (S. aureus) was $21 \%$ and these patients remained in hospital for an average of 13 days. ${ }^{5}$

Local redness, tenderness at insertion site and fever are less specific and sensitive to diagnose catheter-related infection. Quantitative blood culture taken from a peripheral vein and culture of the tip of central venous catheter can be used to diagnose catheter related infection. Patients in whom CRI IS suspected sample for culture should be drawn from catheter and from a peripheral vein. ${ }^{6} \mathrm{~A}$ meta-analysis in 2005 it found that quantitative blood cultures from both sites (peripheral and central) were more accurate to diagnose catheter related infection. ${ }^{7}$ Positive blood culture of sample taken from peripheral site will be useful to diagnose infection while results of sample taken from central catheter are awaited. Earlier growth is likely in blood taken from central 
venous catheters as compared to peripheral vein. Positive culture of blood taken from catheter that came positive before peripheral blood was $91 \%$ more sensitive and $94 \%$ more specific in diagnosing infection. ${ }^{8}$ Infection of central venous catheter can also be diagnosed by sending catheter tip for culture. In a study by Haq et al, catheter related blood infection was found in 14\% of patients. ${ }^{9}$ Another study by Murea et al, showed fewer catheter related infections in young patients compared to old age patients. ${ }^{10}$

In multiple studies it has been shown that hemodialysis patients who have had infection of their central venous catheters suffered huge economic burden on an average cost of $\$ 23,451$ per hospitalization. ${ }^{11}$

The aim of this study is to determine the frequency of catheter-related infection in a third world low income country like Pakistan. It is very important to know the burden of this condition as it imparts a great financial burden on the patient and on the overall health care system bit in terms of cost and hospital bed occupancy. By determining the frequency of catheter related infections it can be emphasized that proper preventive measures can be taken and better protocols can be developed to prevent this highly costly complications as education and prevention was cost effective rather than treating. ${ }^{12}$

\section{MATERIALS AND METHODS}

Patients undergoing hemodialysis via double lumen central-venous line at the department of nephrology was included in the study after informed and written consent. Patients name, age, gender, medical record number, time since commencement of hemodialysis via double lumen catheter and site of the double lumen catheter was noted, Regular monitoring of temperature and WBC counts was carried out. If a patient develops fever (100 F or more) or leukocytosis (TLC $12,000 / \mathrm{mcl}$ ), a through re-examination, urinalysis and chest $\mathrm{x}$-ray was done to exclude other causes of infection in this patient. Blood cultures from catheter tip and a peripheral blood culture was sent. Growth of the organism from both the cultures was noted and catheter related infection was termed positive if same organism s found to be present in both the cultures. Data was collected on a prescribed proforma. Frequency and percentage was calculated for gender, site of catheter and catheter related infection. Mean $+/$ - SD was calculated for age and time since commencement of hemodialysis via double lumen catheter. Stratification was done for the outcome according to age, gender, site of catheter and time since commencement of dialysis via double lumen catheter, age and time was divided into groups and Chi square was applied. $P$ value of $\leq$ 0.05 was taken as significant.

\section{RESULTS}

Mean age of the patients was $42.69 \pm 6.86$ years. Majority of the patients 111 (86\%) were presented with $>40$ years of age.

There were 75 (58.10\%) females and 54 (41.90\%) males.

Mean time since commencement of hemodialysis via double lumen catheter was $27.08 \pm 1.73$ days. Majority 96 (74.40\%) of the patients had $\leq 27$ days since commencement of hemodialysis via double lumen catheter.

In majority of the patients, site of catheter was right internal jugular vein 54 (41.90\%), followed by femoral vein 30 (23.30\%), left internal jugular vein 24 (18.60\%) and subclvian vein in 21 (16.30\%) patients. (Figure-1)

Fever/leukocytosis was observed in 22 (17.10\%) patients while positive blood culture was found in $19(14.70 \%)$ patients.

Frequency of catheter related infection was found to be 19 (14.70\%). (Figure-2)

Stratification was done with respect to age, time since commencement of hemodialysis via double lumen catheter, gender and site of catheter with the outcome. Chi-square test was applied. Results are shown in Table-I 


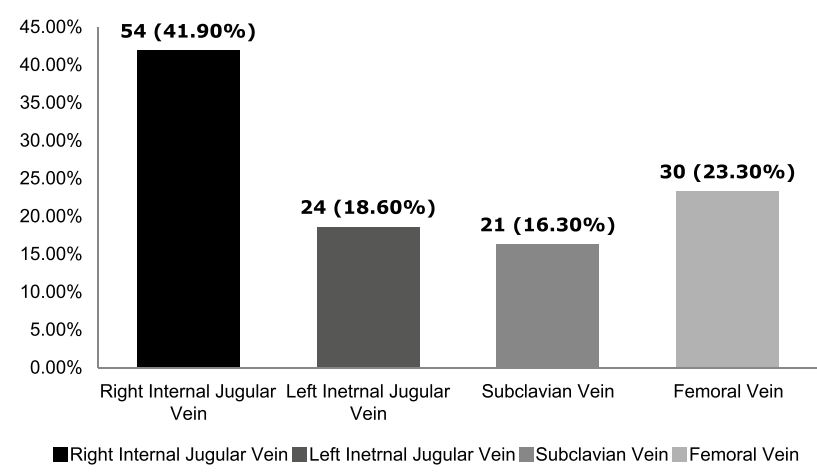

Figure-1. Site of catheter

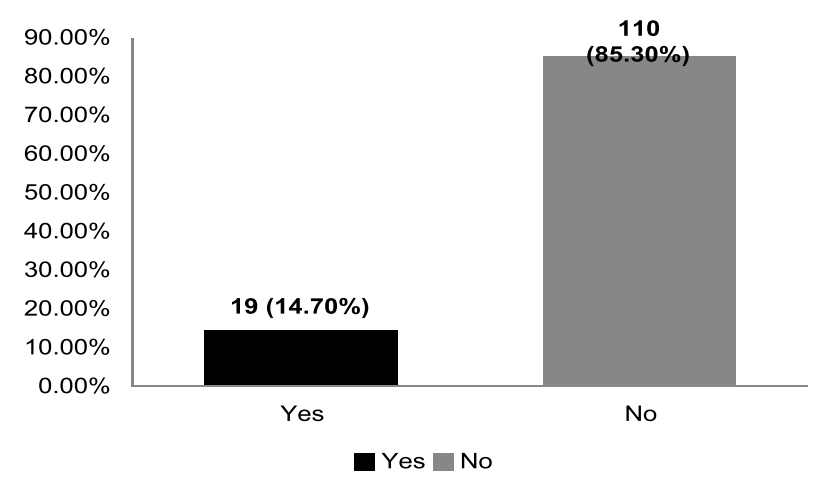

Figure-2. Catheter related infection

\begin{tabular}{|c|c|c|c|c|}
\hline \multirow{2}{*}{ Site of Catheter } & \multicolumn{2}{|c|}{ Catheter Related Infection } & \multirow{2}{*}{ Total } & \multirow{2}{*}{ p-value } \\
\hline & Yes & No & & \\
\hline Right Internal Jugular Vein & $7(13)$ & $47(87)$ & $54(100)$ & \multirow{5}{*}{0.960} \\
\hline Left Internal Jugular Vein & $4(16.7)$ & $20(83.3)$ & $24(100)$ & \\
\hline Subclavian Vein & $3(14.3)$ & $18(85.7)$ & $21(100)$ & \\
\hline Femoral Vein & $5(16.7)$ & 25 (83.3) & $30(100)$ & \\
\hline Total & $19(14.7)$ & $110(85.3)$ & $129(100)$ & \\
\hline
\end{tabular}

Table-I. Comparison of site of catheter with catheter related infection $n=129$

\section{DISCUSSION}

Hemodialysis patients with central venous catheters are at increased risk of morbidity and mortality due to bacteremia with an average risk of 5.5 episodes per 1000 catheter days. ${ }^{3}$ In one study the rate of death was 34\%.4 Bacteremia with Staphylococcus aureus ( $S$. aureus) was responsible in $21 \%$ patient and the stay in hospital was on an average of 13 days. ${ }^{5}$ Local redness, tenderness at insertion site and fever are less specific and sensitive to diagnose catheterrelated infection. Quantitative blood culture taken from a peripheral vein and culture of the tip of central venous catheter can be used to diagnose catheter related infection. Patients in whom CRI IS suspected sample for culture should be drawn from catheter and from a peripheral vein. ${ }^{6} \mathrm{~A}$ metaanalysis in 2005 it found that quantitative blood cultures from both sites (peripheral and central) were more accurate to diagnose catheter related infection. ${ }^{7}$ Positive blood culture of sample taken from peripheral site will be useful to diagnose infection while results of sample taken from central catheter are awaited. Earlier growth is likely in blood taken from central venous catheters as compared to peripheral vein. Positive culture of blood taken from catheter that came positive before peripheral blood was $91 \%$ more sensitive and $94 \%$ more specific in diagnosing infection. ${ }^{8}$ Infection of central venous catheter can also be diagnosed by sending catheter tip for culture.

In our study, frequency of catheter related infection was found to be 19 (14.70\%). In a study by $\mathrm{Haq}$ et al, catheter related blood infection was found in $14 \%$ of patients. ${ }^{9}$ Another study by Murea et al, showed fewer catheter related infections in young patients compared to old age patients. ${ }^{10}$

There is a large economic and clinical impact of catheter-related infections in hemodialysis patients which has been quantified by various studies. One study looked at the average cost for male patients on hemodialysis the cost was estimated at $\$ 23,451$ per hospitalization. ${ }^{11}$ The microorganisms with natural habitat in the skin are commonly found in catheter infection. In fact the Staphylococcus epidermidis coagulase-negative group, present all over the skin leads to more than half of the CRI. We can prevent infection by proper Hand washing and disinfection of the insertion sites. The most reported microorganisms in CRBSI are Gram-positive organisms of the skin. ${ }^{13}$ In some parts of the world catheter related infection caused by Gram-negative organisms. ${ }^{14}$ 
The immune deficient patients are more prone for Candida fungal infection of their central venous catheters. ${ }^{15}$ Central venous catheters were very important part of care of patients on hemodialysis until catheter-related complications became obvious. Infection in central venous catheter causes more morbidity and life threatening complications in hemodialysis patients. ${ }^{16}$ The incidence of bacteremia is 0.5 to 13 per 1000 patient-days with central venous catheters. The rate of infection is low with permanent silicone catheters and high rate is observed with temporary polyurethane catheters. Central venous catheters are being used in Chronic Kidney Disease 5 patients for extracorporeal therapy. There are two indications for their use: first, for short-term use when patient has no permanent angioaccess for hemodialysis or when AVF or AVG needs correction, second, for longterm use when patient has no native vessel of required caliber for the creation of arteriovenous fistula and in some situations like heart failure, severe arterial insufficiency or elderly patients with poor outcome. Blood-stream infections due to hemodialysis catheters cause significant morbidity and catheter withdrawals in up to onethird of patients. The incidence of catheter-related infection averages 8.7 per 1000 catheter-days. ${ }^{17}$ The site of catheter insertion plays a significant role in the magnitude of the infectious risk. The femoral route is apparently less favorable than subclavian or jugular routes.

\section{CONCLUSION}

The frequency of catheter related infection was found in 19 (14.70\%) patients undergoing hemodialysis via double-lumen catheter.

\section{Copyright@ 16 May, 2019.}

\section{REFERENCES}

1. Grothe C, Da Silva Belasco AG, De Cassia Bittencourt AR, Vianna LAC, De Castro Cintra Sesso R, Barbosa DA. Incidence of blood stream infection among patients on hemodialysis by central venous catheter. Rev Lat Am Enfermagem. 2010 Feb; 18(1):73-80.

2. Tokars Jl, Miller ER, Alter MJ, Aruduino MJ. National surveillance of dialysis-associated disease in the United States, 1997. Semin Dial. 2000 Apr; 13(2):7580.
3. Saad TF. Bacteremia associated with tunnelled, cuffed hemodialysis catheters. Am. I. Kidney Dis. 1999 Dec; 34(6): 1114-24.

4. Danese MD, Griffiths RI, Dylan M, Yu H-T, Dubious R, Nissenson AR. Molarity differences among organisms causing septicaemia in hemodialysis patients. Hemodial Int. 2006 Jan; 10(1): 56-62.

5. Nissenson AR, Dylan ML, Griffiths RI, Yu H-T, Dean BB, Danese MD, et al. Clinical and economic outcomes of Staphylococcus aureus in ESRD patients receiving hemodialysis. Am. J. Kidney Dis. 2005 Aug; 46(2): 3018.

6. Mermel LA, Farr BM, Sherertz RJ, Raad II, O' Grady N, Harris JS, et al. Guidelines for the management of intravascular catheter-related infections. Clinn infect dis. 2001 May 1; 32(9): 1249-72.

7. Safdar N, Fine JP, Maki DG. Meta-analysis: Methods for diagnosing intravascular device-related bloodstream infection. Ann intern Med. 2005 Mar 15; 142(6): 451-66.

8. Blot F, Schmidt E, Nitenberg G, Tancrede C, Leclercq B, Laplanche A, et al. Earlier positivity of central-venousversus peripheral-blood cultures is highly predicitive of catheter-related sepsis J. Clin. Microbial. 1998 Jan; 36(1): 105-9.

9. Quershi AL, Abid K. Frequency of catheter related infections in hemodialysed ureamic patients. J Pak Med Assoc. 2010 Aug; 60(8):671-5.

10. Haq J, Fatea K, Faruq M, Mansur F, Barai L, Karim M. Intravascular catheter-related infections and antimicrobial suspectibility pattern of isolated bacteria in a tertiary care hospital of Bangladesh. Indian Journal of Medical Microbology. 2014; 32(1):68.

11. Murea M, James KM, Russell GB, Byrum GV, Yates JE, Tuttle NS, Bleyer AJ, Burkart JM, Freedman BI. Risk of catheter-related bloodstream infection in elderly patients on hemodialysis. Clinical Journal of the American Society of Nephrology. 2014 Apr 7;9(4):76470.

12. Ramanathan V, Chiu EJ, Thomas JT, Khan A, Doslon GM, Darauiche RO. Healthcare costs associated with hemodialysis catheter-related infections: A singlecentre experience. Infect control Hosp Epidemiol. 2007 May; 28(5): 606-9.

13. Suzuki M, Satoh N, Nakamura M, Horita S, Seki G, Moriya K. Bacteremia in hemodialysis patients. World J Nephrol. 2016 Nov 6; 5(6): 489-496. 
14. Allegranzi B, Bagheri Nejad S, Combescure C, Graafmans W, Attar $\mathrm{H}$, et al. Burden of endemic healthcare-associated infection in developing countries: Systematic review and meta-analysis. Lancet. 2011; 377: 228-41.

15. SB Stephanie, Madison B, RS Susan, HD James, EC Nancy, AS Michael et al. Effectiveness of Practices To Increase Timeliness of Providing Targeted Therapy for Inpatients with Bloodstream Infections: A Laboratory Medicine Best Practices Systematic Review and Meta-analysis. Clin Microbiol Rev. 2016 Jan; 29(1):59-103
16. Kosa SD, Gafni A, House AA, Lawrence J, Moist L, Nathoo $B$. et al Hemodialysis infection prevention protocols ontario-shower technique (HIPPO-ST): A pilot randomized trial. Kidney Int Rep. 2017 Mar; 2(2):228-38.

17. Rathi M, Pinnamaneni VST, Sakhuja V. Non-imaging assisted insertion of un-cuffed, non-tunneled internal jugular venous catheters for hemodialysis: Safety and utility in modern day world. Biomed J 2016 Aug; 39(4):283-8.

\begin{tabular}{|c|l|l|l|}
\hline \multicolumn{2}{|c|}{ AUTHORSHIP AND CONTRIBUTION DECLARATION } \\
\hline Sr. \# & \multicolumn{1}{|c|}{ Author-s Full Name } & Contribution to the paper & Author=s Signature \\
\hline 1 & Muhammad Ali & Data collection. \\
\hline 2 & Bhagwan Das & Research methodology. \\
\hline 3 & Santosh Kumar & Data analysis. \\
\hline 4 & Rafia Memon & PG \\
\hline 5 & Bella Dayu & Babeeta & PG \\
\hline
\end{tabular}

